\title{
Visually evoked cortical potentials from different cortical regions in humans
}

\author{
PHILIP M. GROVES AND ROBERT G. EASON $I$ \\ SAN DIEGO STATE COLLEGE AND NAVY ELECTRONICS LABORATORY
}

Visually evoked cortical potentials were recorded simultaneously from occipital, parietal, temporal and frontal electrode placements utilizing surface scalp-electrodes. Amplitude measures indicated that the largest response occurred at the occipital electrode site. However, the occipital response had the longest average latency.

Visual evoked cortical potentials vary considerably with the type of stimulus employed. A bright flash, subtending a wide visual angle, will evoke potentials with complex waveforms which exhibit components as early as 15-40 msec after the flash (Ciganek, 1958, 1961; Kooi \& Bagchi, 1964; White \& Eason, 1966). A dim, foveal stimulus evokes a relatively simple sinusoidal response with a frequency of 8-12 cps which does not exhibit these early components (Eason, Oden, \& White, 1967). The early components of the response have been attributed to the specific visual system while the later sinusoidal component has been attributed to a more diffuse, nonspecific system (Cigánek, 1961).

Studies of electrode placements, utilizing the bright flash, have indicated that the onset latency of the response is shortest over the occipital region which, in general, yields the largest response (Vanzulli et al, 1960; García-Austt et al, 1961; Kool \& Bagchi, 1964). However, if two neural systems are involved in the elaboration of the primary and secondary responses, the time relations and amplitude differences observed with the bright stimulus might not hold in the case of the dim, foveal stimulus. The purpose of the present study was to investigate the cortical distribution of the late response, characteristic of the foveal stimulus, in an effort to further our understanding of its neural basis.

Method

Eighteen male undergraduate and graduate students served as subjects (Ss). Each $\mathrm{S}$ participated in four recording sessions during which potentials were recorded simultaneously from occipital, parietal, temporal, and frontal electrode placements. The occipital electrode was placed $2.5 \mathrm{~cm}$ above and to the right of the inion. The parietal electrode was placed $2.5 \mathrm{~cm}$ posterior to and $3 \mathrm{~cm}$ to the right of the vertex. The frontal electrode was placed $3 \mathrm{~cm}$ to the right of the midline of the scalp and $3 / 4$ of the distance from the inion to the nasion. The temporal electrode was $1 \mathrm{~cm}$ anterior to and $6.5 \mathrm{~cm}$ above the tragus. The reference electrode for these scalp electrodes was placed on the right ear lobe. Potentials were averaged with a Mnemo- trom Computer of Average Transients, each average being based on 200 light flashes. Control recordings indicated that potentials recorded during the experimental trials reflected the true cortical responses evoked by the light flashes.

Stimulus flashes of $10 \mu \mathrm{sec}$ duration were projected through a red filter (Kodak Wratten filter No. 29) onto the center of a hemispheric screen having a background

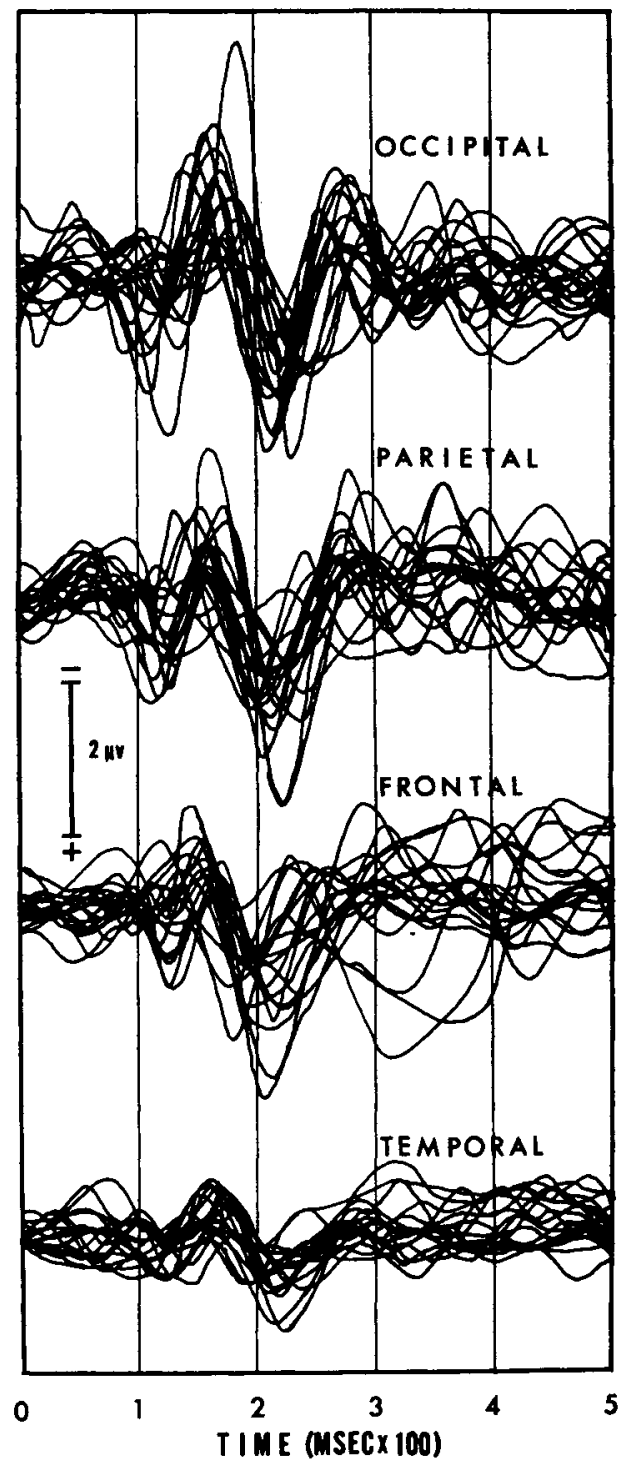

Fig. 1. Superimposed tracings of the evoked responses obtained from 18 Ss. Each tracing is based upon the average of 200 light-flash evoked potentials. 
luminance of $2 \mathrm{~mL}$. Both eyes were stimulated foveally as $\mathrm{S}$ fixated the center of the screen. The flashes subtended a visual angle of $1^{\circ}$, their brightness being approximately $1 \mathrm{log}$ unit above S's threshold. The details of recording and stimulation techniques have been reported elsewhere (Eason, Oden, \& White, 1967). Results and Discussion

Figure 1, which shows the evoked responses obtained in one of the sessions for each $\mathrm{S}$, is illustrative of the results obtained in all sessions. Superimposed tracings of the responses obtained from the $18 \mathrm{Ss}$ for a given electrode site reveal the existence of a characteristic pattern. A positive (downward) deflection starts at about $90 \mathrm{msec}$, followed by a negative (upward) deflection beginning at about $125 \mathrm{msec}$. Another positive deflection begins at about $165 \mathrm{msec}$, followed by alternating deflections at approximately $50 \mathrm{msec}$ intervals. The largest and most obvious deflections in all the records occurred between 125 and $290 \mathrm{msec}$ after the stimulus flash.

An average amplitude was calculated for each $S$ on each session for each electrode site by measuring the vertical peak-to-trough distances covered by the three major deflections, summing the three values and taking the average. An analysis of variance performed on these data indicated that the amplitudes of potentials from the four electrode locations varied more than would be expected by chance $(F=30.5, d f=3 / 51, p<.01)$. A subsequent Newman-Keuls studentized range test indicated that the average amplitudes of potentials from the four areas differed significantly from one another $(p<.01)$. The occipital potentials were largest with a mean amplitude of $2.02 \mu \mathrm{V}$, followed by the mean parietal value of $1.65 \mu \mathrm{V}$. This in turn was larger than the mean frontal value of $1.26 \mu \mathrm{V}$, followed by the mean temporal amplitude of $0.85 \mu \mathrm{V}$. Also revealed by the analysis of variance was a significant subject by electrode site interaction $(F=8.9, d f=162 / 51, p<.01)$, indicating that some Ss showed dissimilar changes in amplitude when the electrode site was varied.

An average latency value for each $S$ on each trial for each lobe was computed by determining the onset time for each of the three major deflections and taking the average. An analysis of variance on these data indicated that the latency values for the four cortical regions varied more than would be expected by chance ( $F=18.7$, $\mathrm{df}=3 / 51, \mathrm{p}<.01$ ). A subsequent Newman-Keuls studentized range test indicated that the response of shortest latency was characteristic of the frontal region with a mean latency of $158.4 \mathrm{msec}$. This mean value was significantly smaller $(p<.01)$ than the mean latencies of the parietal and temporal areas that did not differ materially from one another. The parietal region had a mean latency of $166.6 \mathrm{msec}$, the temporal area a mean of $165.5 \mathrm{msec}$. The mean latency of the occipital region was significantly longer than the other three regions $(p<.01)$ with a mean of $171.1 \mathrm{msec}$. A significant subject by electrode site interaction $(F=1.5$, $\mathrm{df}=162 / 51, \mathrm{p}<.05)$ reflected the fact that a few Ss showed latency differences at variance with the general findings.

In agreement with previous investigations, the largest response occurred at the occipital electrode placement. However, this response had a considerbly longer average latency than other regions. The early components of the visual evoked potential, if they reflect specific visual activity, might be expected to occur soonest over the occipital cortex. The longer latency of the late response as well as its widespread cortical distribution support the notion that a more diffuse system is involved in its elaboration. The distribution, time relations, and frequency of the late response suggest that it may result from neural activity similar to that responsible for the spontaneous alpha ahythm of normal man. One likely source for the late response in $\operatorname{man}_{8}$ therefore, might be the unspecific thalamic projection system (Jasper, 1959).

\section{References}

CIGÁNEK, L. Potentiels corticaux chex l'homme evoques par les stimuli photiques. Rev. Neurol., 1958, 99, 194-196.

CIGÁNEK, L. The EEG response (evoked potential) to light stimulus in man. EEG clin. Neurophysiol, 1961, 13, 165-172.

EASON, R. G., ODEN, D., \& WHITE, C. T. Visually evoked cortical potentials and reaction time in relation to site of retinal stimulation. EEG clin. Neurophysiol., 1967, 22, 313-324.

GARCIA-AUSTT, E., BOGACZ, J., \& VANZULLI, A. Significance of the photic stimulus on the evoked responses in man. In A. Fessar, R. W. Gerard, \& J. Konorski (Eds.), Brain mechanisms and learning. Oxford: Blackwell Co., 1961.

JASPER, H. H. Unspecific thalamocortical relations. In J. Field, H. W. Magoun, \& V. E. Hall (Eds.), Handbook of physiology. Sect. I., Washington, D. C.: Amer. Physiol. Soc., 1959.

KOOI, K. A., \& BAGCHI, B. K. Visual evoked responses in man: Normative data. Annals N. Y. Acad. Sci., 1964, 112, 254-269.

VANZULLI, A., BOGACZ, J., HANDLER, P., \& GARCÍA-AUSTT, E. Evoked responses in man: I' Photic responses. Acta neurol Latinoamer., 1960, 6, 219-231.

WHITE, C. T., \& EASON, R. G. Evoked cortical potentials in relation to certain aspects of visual perception. Psychol Monogr., 1966, 80, 1-14.

\section{Notes}

1. Address correspondence to R. G. Eason, U. S. Navy Electronics Laboratory, San Diego, California, 92152.

2. This work was supported in part by NSF grant GB-4067. 